\title{
Inhibition of Memory Consolidation After Active Avoidance Conditioning by Antisense Intervention with Ependymin Gene Expression
}

\author{
Rupert Schmidt, *Wolfgang Brysch, Stefan Rother, and †Karl-Hermann Schlingensiepen
}

\author{
AK Neurochemie, Zoologisches Institut, Biozentrum der J. W. Goethe-Universität, Frankfurt am Main; *Biognostik GmbH, \\ Göttingen; and †Abteilung Neurobiologie, Max-Planck-Institut für biophysikalische Chemie, Göttingen, Germany
}

\begin{abstract}
A rapid increase in ependymin mRNA expression demonstrated by semiquantitative in situ hybridization after avoidance conditioning on goldfish suggested a molecular demand for newly synthesized ependymin translation product. To inhibit de novo synthesis of ependymin molecules without interference with preexisting ones, 18 mer anti-ependymin mRNA-phosphorothioate oligodeoxynucleotides (S-ODNs) were injected into the perimeningeal brain fluid before active avoidance training. S-ODN-injected animals learned the avoidance response; however, they were amnesic in the test. When injected into overtrained animals, S-ODNs did not interfere with retrieval or performance of the avoidance response. Fish treated with randomized S-ODN sequences served as further controls. Incorporation of S-ODNs was analyzed by injection of fluorescein isothiocyanate (FITC)-conjugated oligodeoxynucleotide probes. Microscopic observation revealed strong FITC-S-ODN fluorescence in reticular-shaped fibroblasts, the only known site of ependymin synthesis. Results demonstrate that selective inhibition of ependymin gene expression in vivo can specifically prevent memory formation. We conclude that in particular the newly synthesized ependymin molecules are involved in memory consolidation, possibly because they have not yet undergone irreversible molecular changes, which have been reported of this glycoprotein in a low-calcium microenvironment. Key Words: Ependymin - Memory and learning - Antisense interventionCell adhesion molecules-Meninges-Fish brain. J. Neurochem. 65, 1465-1471 (1995).
\end{abstract}

The turnover of a CNS-specific HNK1-bearing cell adhesion glycoprotein, ependymin, increases during periods of neural plasticity, such as regeneration of the optic tract and memory consolidation after operant and classical conditioning paradigms (for references, see Rother et al., 1995). Recently, ependymin mRNA expression was analyzed by semiquantitative in situ hybridization. The ependymin mRNA level was increased $20 \mathrm{~min}-4 \mathrm{~h}$ after acquisition of an active avoidance response (Rother et al., 1995). Enhanced mRNA expression was followed by enhanced trans- lation, secretion, and redistribution of the protein (Schmidt, 1987, 1989). In contrast, yoked control animals exhibited a strong down-regulation of the ependymin message. Ependymin mRNA was exclusively localized to reticular-shaped fibroblasts of the endomeninx. Immunoelectron microscopic investigations, however, detected the translated protein also in cells where no ependymin mRNA was found, namely, in distinct glial cell populations (in particular, ependymal and radial glial cells) and in neurons, such as type I and type XIV neurons of the superficial plexiform and the periventricular cell layers, respectively (Schmidt, 1989; Schmidt et al., 1990; Rother et al., 1995). Redistribution of meningeal protein factors by extracellular brain fluids and their interaction with glial and neuronal cells may therefore provide a functional step in the mechanisms that consolidate plastic adaptations of the CNS.

In accordance with this notion, intracerebroventricular injection of specific anti-ependymin antisera $0.5-$ $24 \mathrm{~h}$ after acquisition of classical (Piront and Schmidt, 1988) or operant (Shashoua and Moore, 1978; Schmidt, 1987) conditioning tasks induced amnesia, whereas injections of the antisera before the learning event were without effect. Furthermore, antisera induced amnesia even if the amount injected [10 $\mu \mathrm{l}$, providing $\sim 0.4 \mathrm{nmol}$ of ependymin binding sites (Schmidt and Shashoua, 1983)] was sufficient to inactivate only a fraction of the total extracellular ependymin content [ $49 \mu \mathrm{g}$, or $>1.6 \mathrm{nmol}$ in a goldfish weighing $8.3 \mathrm{~g}$ (Schmidt and Lapp, 1987)]. In radioimmunoassays, some of our anti-ependymin antisera

Received January 11, 1995; revised manuscript received April 5, 1995; accepted April 6, 1995.

Address correspondence and reprint requests to Dr. R. Schmidt at AK Neurochemie, Zoologisches Institut, Biozentrum der J. W. Goethe-Universität, Marie-Curie-Strasse 9, D-60439 Frankfurt am Main, Germany.

Abbreviations used: FITC, fluorescein isothiocyanate; PBS, phosphate-buffered saline; RS, retention score; S-ODN, phosphorothioate oligodeoxynucleotide; TTC, trials to criterion. 
do not recognize the disulfide-bridged dimeric forms of ependymin, which contribute $>96 \%$ to the extracellular ependymin under physiological conditions (Schmidt and Shashoua, 1981), yet these antisera induce amnesia. Presumably, dimeric ependymins are not directly involved in biochemical reactions of memory consolidation.

Several results obtained with the interventive experimental approach suggested therefore that in particular the newly synthesized ependymin molecules are involved in memory consolidation. Here, this hypothesis was tested by antisense intervention using specific deoxynucleotide probes that inhibit de novo synthesis of ependymin molecules but do not interfere with preexisting ones. This new approach has become possible with the development of phosphorothioate oligodeoxynucleotide ( $\mathrm{S}-\mathrm{ODN}$ ) derivatives that are relatively stable against degradation by endogenous nuclease activities (Eckstein, 1983; Schlingensiepen and Brysch, 1992; Brysch and Schlingensiepen, 1994). Some of the results have previously been published in abstract form (Schmidt et al., 1993).

\section{MATERIALS AND METHODS}

\section{Chemicals}

Ethyl $m$-aminobenzoate methanesulfonate (Tricaine methanesulfonate; MS-222), fluorescein isothiocyanate (FITC)dextran $(10 \mathrm{kDa})$, and methylene blue were bought from Sigma (Deisenhofen, Germany). 2-Methylbutane was purchased from Fluka (Buchs, Switzerland). Other chemicals were those listed by Rother et al. (1995).

\section{S-ODN probes}

Highly purified antisense S-ODNs (Biognostik, Ltd., Göttingen, Germany) were used for in vivo experiments. All oligonucleotides had been analyzed by polyacrylamide gel electrophoresis and ion-exchange chromatography (Warren and Vella, 1993). To inhibit specifically expression of ependymin, a phosphorothioate derivative of the $18 \mathrm{mer}$ oligodeoxynucleotide 5'-CTGTATGCATCATTGCTC-3' (SODN) complementary to ependymin mRNA (Königstorfer et al., 1989) was synthesized (Schlingensiepen and Brysch, 1992 ) for injection into goldfish brain. A randomized 18 mer S-ODN sequence, 5'-ACTACTACACTAGACTAC-3', was synthesized as a control.

\section{Goldfish conditioning}

Goldfish (Carassius auratus) were obtained from TagisAquarium (Dreieich-Sprendlingen, Germany) and kept at $20^{\circ} \mathrm{C}$ in $80-\mathrm{L}$ tanks at least 6 weeks before the experiments. Three days before training, four fish that could easily be distinguished by their coloring were removed from the home tanks and placed into small tanks with aerated water at $28^{\circ} \mathrm{C}$. One day before training they were again moved to another tank, now at $33^{\circ} \mathrm{C}$. They were coded and stochastically assigned to three different groups, i.e., controls, antisense recipients, and recipients of random probes (see below), but were kept together and trained on the same day. All fish were trained identically in a shuttle-box to cross a hurdle to avoid mild electric shocks (unconditioned stimulus) administered $20 \mathrm{~s}$ after a light signal (conditioned stimulus) as described previously (Piront and Schmidt, 1988). A compu- terized shuttle-box was designed and built for this purpose by M. Brümmer and G. Strieder (Universität Frankfurt). The computer (Apple, Cupertino, CA, U.S.A.) controlled the application of conditioned and unconditioned stimuli, recorded the animals' responses via light barriers, and evaluated them on-line. Training sessions were automatically terminated as soon as fish matched a learning criterion of eight correct avoidance responses within $\leq 10$ consecutive trials; these fish were considered "learners." Fish that did not reach the learning criterion within 40 trials were not used further in behavioral experiments.

Learners were returned to their tanks within 15 min after acquisition of the task. Three days later, they were again exposed to the shuttle-box and tested for recall by means of a retraining procedure. A retention score (RS) was calculated (described below) from the savings, i.e., from the reduction in the number of mistakes made during the test as compared with the training session.

At $18 \mathrm{~h}$ before training experimental fish were injected with $9 \mu \mathrm{l}$ of phosphate-buffered saline (PBS; $123 \mathrm{mM} \mathrm{NaCl}$ and $10 \mathrm{~m} M$ phosphate, $\mathrm{pH} 7.2$; isoosmolar to goldfish brain extracellular fluid) containing $0.3 \mathrm{nmol}$ of either antisense S-ODN or randomized S-ODN. For this purpose fish were anesthetized in $0.01 \%$ Tricaine methanesulfonate for $5 \mathrm{~min}$. Then a scale was removed $2 \mathrm{~mm}$ dorsal to the cranial cavity, and a microsyringe (701 N; Hamilton, Bonaduz, Switzerland) was horizontally introduced into the cranial cavity to position the tip in the large reservoir of perimeningeal fluid above the optic tectum. Just below this site of injection the leptomeninx is densely packed with reticular-shaped fibroblasts expressing ependymin mRNA (compare Fig. 5 and Rother et al., 1995). Pilot experiments, in which fish were injected with methylene blue in PBS, revealed, however, that the dye also diffused quickly into the neural parenchyma and the cerebroventricular fluid. S-ODNs were slowly injected, $9 \mu \mathrm{l}$ in $\sim 2 \mathrm{~min}$. Fish were returned to their tanks immediately after the injection, and they recovered quickly (2-4 min) from anesthesia. One hour before training fish were injected with a second dose $(0.3 \mathrm{nmol}$ in $9 \mu \mathrm{l})$ of antisense or random S-ODN, respectively. As goldfish tolerate rather high water temperatures, fish were kept at $33^{\circ} \mathrm{C}$ from $24 \mathrm{~h}$ before the first training until the end of the test session to facilitate RNA hybridization.

Following the test in the shuttle-box, fish from the uninjected control group were retrained every 4 days. After three training procedures, few fish made more than two mistakes per session. At 18 and $1 \mathrm{~h}$ before the 10th session, when fish were regarded as well "overtrained," they were twice injected with antisense S-ODN against ependymin mRNA (at $33^{\circ} \mathrm{C}$, like experimental animals) and tested again, 3 days after the 10 th session.

\section{RS values}

For quantitative evaluation of behavioral tests, RS values were calculated by the algorithm of Piront and Schmidt (1988), which relates the number of trials to reach the criterion of $\geq 80 \%$ correct responses in the test session to the number of trials to criterion (TTC) in the training session (after subtraction of the final eight correct responses): $\mathrm{RS}=\left[\left(\mathrm{TTC}_{\text {training }}-8\right)-\left(\mathrm{TTC}_{\text {test }}-8\right)\right] /\left[\left(\mathrm{TTC}_{\text {training }}-8\right)\right.$ $\left.+\left(\mathrm{TTC}_{\text {test }}-8\right)\right]$. The equation assigns an RS of 1.0 to animals exhibiting immediate recall and an RS of 0.0 to animals that show no improvement over training in the test. Negative RS values are attributed to fish making more mistakes in the test than in the training session. It has earlier 
been shown that fish do not further improve their individual avoidance performance, once they have reached the learning criterion. The computer was programmed therefore to use the level of performance during the last eight trials to extrapolate data to 25 cycles for calculation and display of averaged responses of grouped fish over the number of trials (see Figs. 1-4)

Behavioral studies were done "blind," i.e., the experimenter did not know whether antisense S-ODNs or randomized S-ODNs were being injected. Fish belonging to the same group, i.e., control, antisense, or random, were neither kept together physically nor trained in series, and the experimenter training and testing the animals did not know to which group an individual fish had been assigned. After calculation of individual RS values, statistically significant differences were established using a two-tailed $t$ test. Only after completion of statistical analyses was the code broken, and groups could now be identified as "control," "antisense," and "random."

\section{Monitoring of oligodeoxynucleotide and dextran uptake}

To monitor whether S-ODNs are incorporated from the perimeningeal fluid into the meninx and brain tissue, the anti-ependymin S-ODN was conjugated to FITC. FITC labeling was performed using a C3-amino-linker (Glen Research), and labeled oligonucleotides (FITC-S-ODNs) were separated from unincorporated product by reversephase HPLC on a C18 column, followed by product peak lyophilization and purification as described previously (Brysch et al., 1995). FITC-S-ODNs were injected twice in exactly the same manner as the unlabeled S-ODNs in behavioral studies. At 90 min after the second injection goldfish were anesthetized by cooling for $5 \mathrm{~min}$ in ice water and killed by decapitation. Brains were quickly removed from the skull and fixed by immersion in isotonic PBS containing $4 \%$ paraformaldehyde. Fixative was then replaced by 10 and $20 \%$ sucrose in PBS (overnight), and brains were frozen in melting 2-methylbutane and cut to $12-\mu \mathrm{m}$-thick sections on

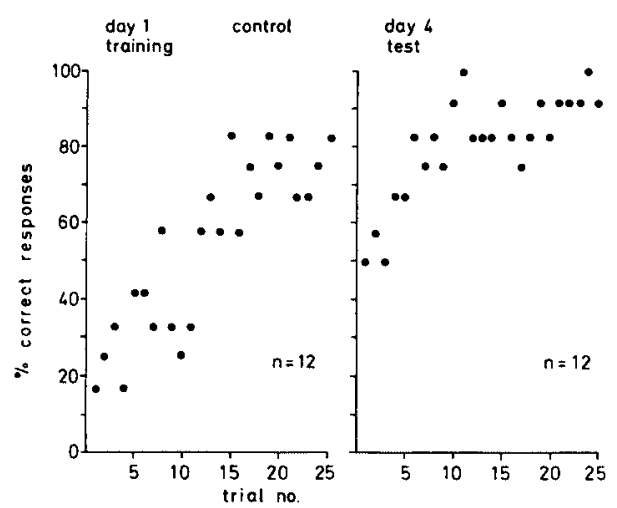

FIG. 1. Averaged behavioral responses of goldfish trained on an active avoidance paradigm in a shuttle-box. Responses were scored correct when the fish crossed a hurdle and moved into the dark compartment of the training tank. Fish remaining in the illuminated portion of the shuttle-box were electrically shocked. It took 25 trials ( 1 min each) in the training session, until fish exhibited a constant behavior with an average of $\geq 80 \%$ correct responses. In the test on day 4 , the group of uninjected goldfish showed retention of the task, and $\geq 80 \%$ correct responses were displayed after nine trials.

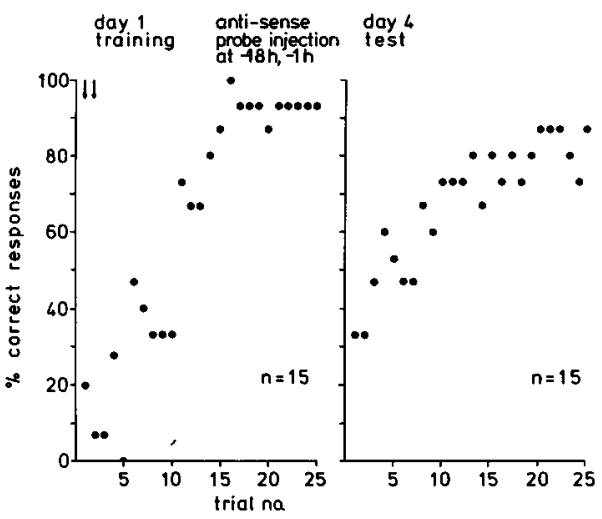

FIG. 2. Training and test of goldfish treated with anti-ependymin oligodeoxynucleotides. To inhibit specifically de novo synthesis of ependymins, fish were injected with antisense S-ODNs into the perimeningeal fluid before training. On day 4, these animals were amnesic; however, they relearned the task in the test session.

a cryostat. Microscopic observations were performed on an Olympus IMT-2 microscope. In additional experiments, goldfish were injected with FITC-dextran (molecular mass $10 \mathrm{kDa}$ ) in PBS into the perimeningeal fluid and killed 24 $\mathrm{h}$ later, to monitor dextran uptake.

\section{RESULTS}

Uninjected control fish trained on the active avoidance paradigm remembered the task when tested 3 days after acquisition (Fig. 1). The average \pm SEM RS was $0.54 \pm 0.10(\mathrm{n}=12)$.

Retention of the active avoidance response in the shuttle-box was strongly inhibited after application of anti-ependymin S-ODN (Fig. 2). The RS of this group amounted to $0.11 \pm 0.15(\mathrm{n}=15)$. The difference between S-ODN-injected and uninjected fish was significant on a confidence level of $p<0.05$ (by Student's $t$ test). In contrast, short-term retention of the task was not disturbed, as fish acquired the avoidance response at a normal speed, i.e., within $\sim 25$ trials. Also, the percentage of fish that mastered the task after S-ODN injection was not significantly different from that of uninjected controls (data not shown). Furthermore, a delayed toxicity of the S-ODN on day 4 was ruled out, because injected fish relearned the avoidance task in the test session.

Pilot experiments using $>200$ goldfish had been performed to establish optimal conditions for antisense intervention. These included in situ hybridizations at $20^{\circ} \mathrm{C}$, injections of underivatized antisense oligodeoxynucleotide probes, injections into brain ventricles instead of the perimeningeal cavity, injections at either 18 or $1 \mathrm{~h}$ before training, injections after acquisition, different lengths and sequences of the oligonucleotides, and different concentrations of the S-ODN probes. Although most of these measures had some influence on retention of the avoidance response (ap- 


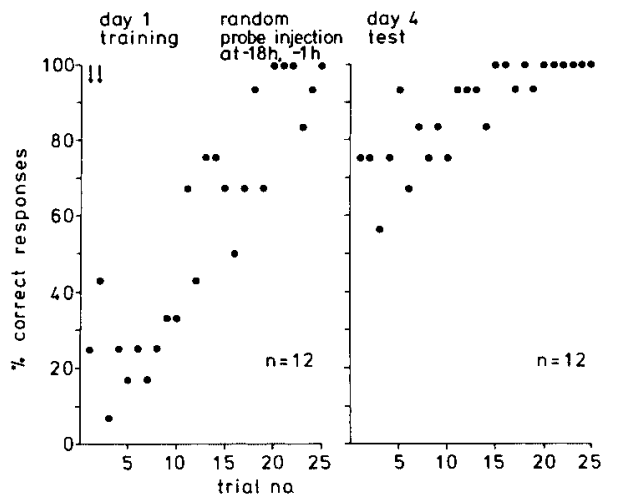

FIG. 3. Control fish treated with a random S-ODN sequence. Goldfish were injected with a randomized S-ODN sequence by the same protocol as used for anti-ependymin S-ODNs. They exhibited retention of the avoidance task identical to that of uninjected controls.

parently with the exception of posttraining injections), amnesia was most reproducibly induced with the final protocol outlined in Materials and Methods.

Fish treated with a randomized S-ODN sequence of equal length served as controls (Fig. 3). They learned and recalled the shuttle-box task as well as uninjected goldfish and achieved a mean \pm SEM RS of 0.52 $\pm 0.10(n=12)$. The difference from anti-ependymin mRNA S-ODN-injected fish was significant on a confidence level of $p<0.05$.

To exclude a possible effect of the antisense probe on retrieval of the conditioned response or on performance of the avoidance behavior as such ("state dependency"), goldfish were trained repeatedly on the task and injected with anti-ependymin S-ODN before the 10th session in the shuttle-box. The antisense probe did not interfere with recall of the task in these over-

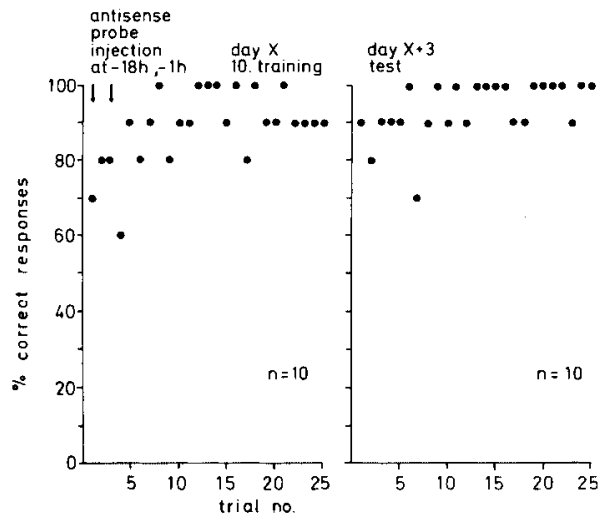

FIG. 4. Testing overtrained animals for a possible effect of antiependymin S-ODNs on retrieval. Goldfish were trained nine times on the avoidance task, injected with antisense S-ODNs, trained, and tested again. The antisense probe did not interfere with recall of the task in these overtrained animals.

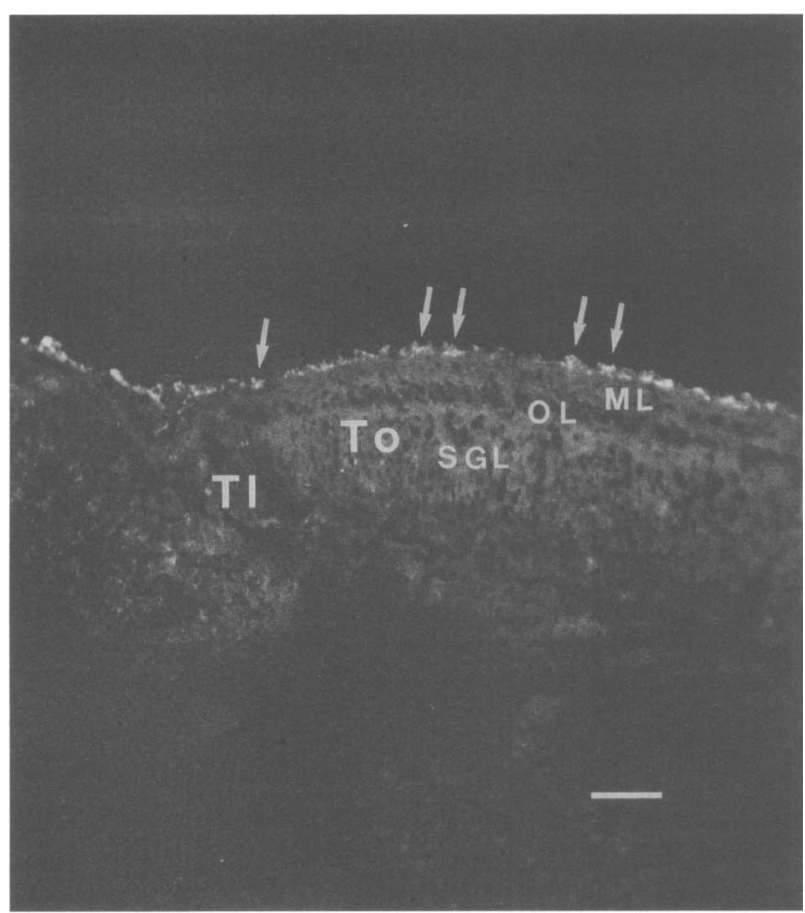

FIG. 5. Incorporation of antisense oligodeoxynucleotides into fibroblasts of the leptomeninx. FITC-S-ODNs directed against ependymin mRNA were injected into the perimeningeal cavity. Most of the label was observed in reticular-shaped fibroblasts (arrows) of the inner endomeningeal cell layer, the only site of ependymin synthesis. ML, marginal layer; OL, optic layer; SGL, superficial gray and plexiform layer; $\mathrm{TI}$, torus longitudinalis; To, tectum opticum. Bar $=70 \mu \mathrm{m}$

trained animals (Fig. 4). Obviously, S-ODNs did not produce brain damage or any long-lasting toxic effect that could account for the retention deficit observed in the experimental group.

It has clearly been demonstrated that oligodeoxynucleotides and S-ODNs pass through cell membranes (compare Brysch and Schlingensiepen, 1994). Still, we tested this assumption with FITC-S-ODN counterparts to ependymin mRNA. FITC-S-ODNs were injected into the perimeningeal cavity of goldfish brain under conditions identical to those used in the behavioral experiments. S-ODNs were readily incorporated into the reticular-shaped fibroblasts of the inner endomeningeal cell layer (Fig. 5; compare Rother et al., 1995). Although a general background staining of the neural parenchyma was observed, most of the injected label was recovered in the ependymin-synthesizing fibroblasts. It is known that oligodeoxynucleotide uptake has several components (Tischmeyer et al., 1994; WuPong et al., 1994). One of the uptake mechanisms is competitive for polyanions such as dextran. To determine whether fibroblasts display this mechanism of uptake, FITC-dextran (molecular mass $10 \mathrm{kDa}$ ) was injected into the perimeningeal fluid (Fig. 6). Again, intense staining was observed in the leptomeninx and 


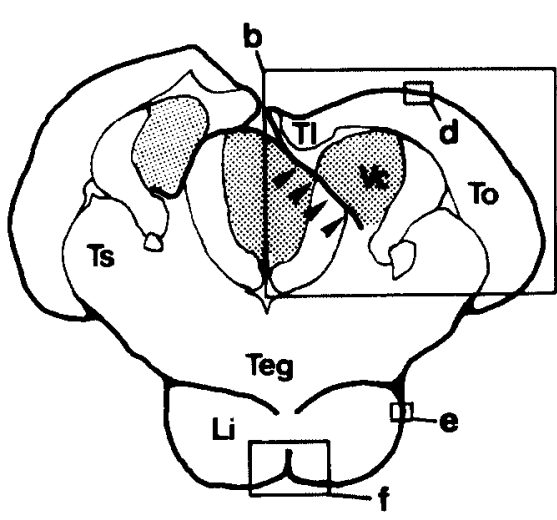

a

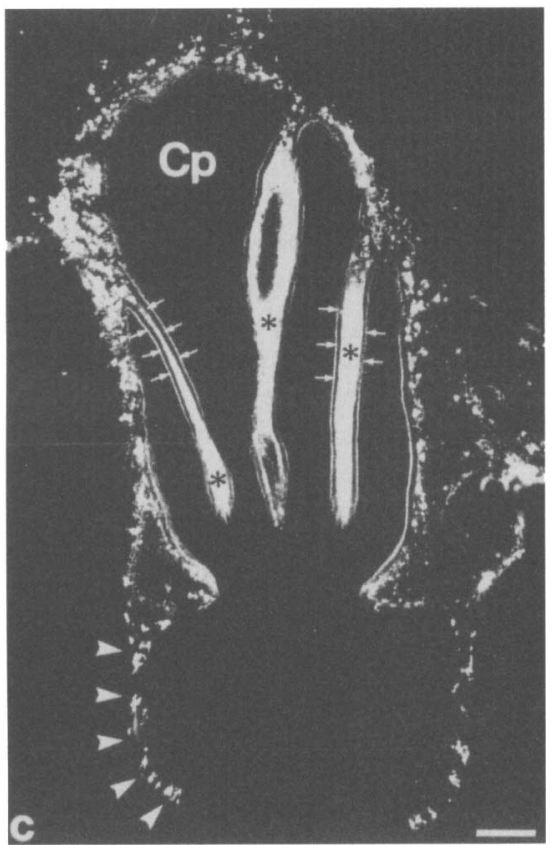

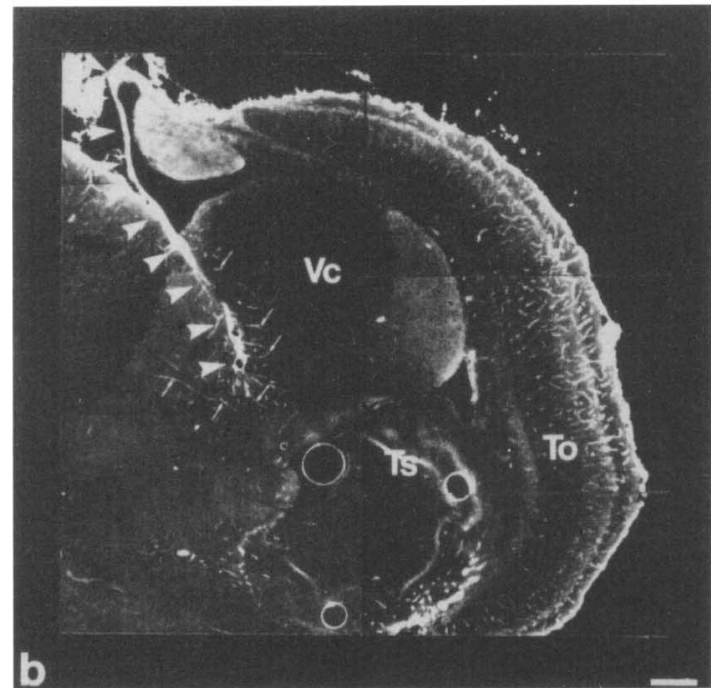
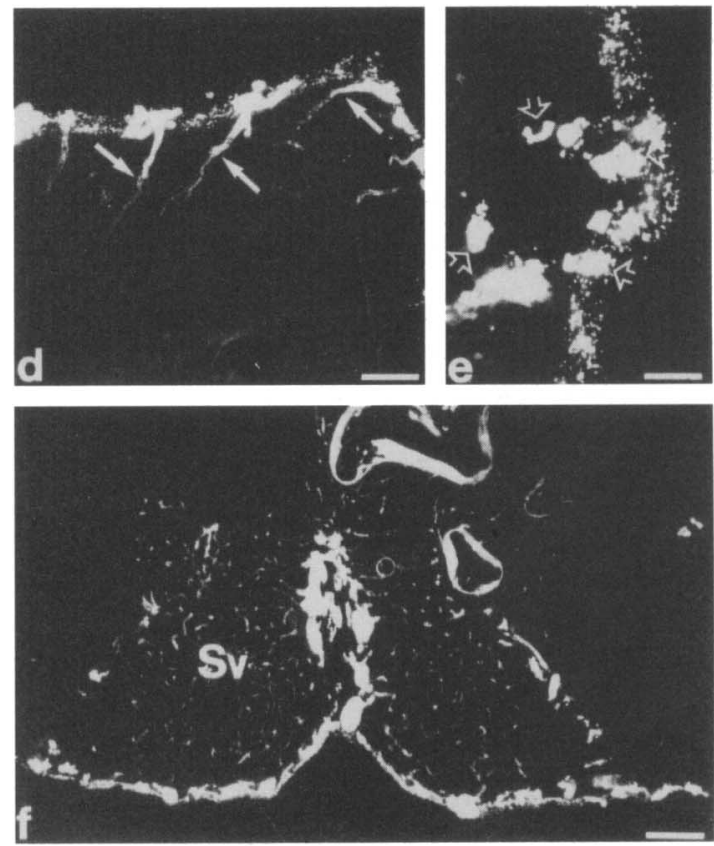

FIG. 6. Uptake of FITC-dextran after injection into the perimeningeal fluid. a: Schematic representation of goldfish optic tectum and diencephalon. Positions of the enlargements shown in some of the other panels are indicated by boxes. Li, inferior lobe; Teg, tegmentum; $\mathrm{TI}$, torus longitudinalis; To, tectum opticum; Ts, torus semicircularis; Vc, valvula cerebelli. Arrowheads point to the endomeningeal invagination into the valvula cerebelli. b: Caudal part of the mesencephalon. Note the intense staining of the meninx and a meningeal invagination (arrowheads). Also, blood vessels are stained (small arrows). Bar $=200 \mu \mathrm{m}$. c: Plexus chorioideus (Cp) between telencephalon and mesencephalon. Fluorescence staining is restricted to the extracellular space (asterisks) between epithelial foldings. The chorioidal epithelium itself is free of dextran label (arrows). Arrowheads point to a leptomeningeal invagination. Bar $=60 \mu \mathrm{m}$. d: Blood vessels extending from the meninx into the marginal layer of the optic tectum are labeled with FITC-dextran (arrows). Bar $=40$ $\mu \mathrm{m}$. e: Meningeal fibroblasts (arrowheads) surrounding a blood vessel. There is intense granular staining in the cytoplasm, indicative of endocytotic uptake of dextran. Bar $=20 \mu \mathrm{m}$. $\mathrm{f}$ : Localization of dextran in the endomeninx and capillaries of the saccus vasculosus (Sv). Bar $=80 \mu \mathrm{m}$.

meningeal invaginations into the brain. A strong granular staining was displayed in reticular-shaped fibroblasts, indicative of endocytotic uptake of the dextran molecules. Many labeled fibroblasts were seen in close proximity to blood vessels. Blood vessels were also stained, in particular those extending (with the perivas- cular space) from the meninx into the neural parenchyma. At these vessels, the intensity of staining faded with the distance from the meninx. In the chorioid plexus staining was restricted to the extracellular space, whereas the chorioidal epithelia were devoid of dextran label. 


\section{DISCUSSION}

The reported experiments demonstrate that antisense intervention with ependymin gene expression inhibits memory consolidation after active avoidance conditioning.

It has long been known from the work of many laboratories that undisturbed protein biosynthesis is a major prerequisite for long-term memory formation after learning events (see, e.g., Hydén and Egyhazi, 1964; Davis and Squire, 1984; Shashoua and Schmidt, 1987). Most of those proteins identified that have yet been shown to display increased synthesis during the memory consolidation process fall into one of three classes: (a) so-called house-keeping enzymes, in particular, those of the cellular energy metabolism, such as glycolytic enzymes (see, e.g., Bock and Dissing, 1975); (b) factors modulating a step in the cascade of biochemical reactions that link receptor activation to a durable cellular response, such as $G$ proteins and regulatory subunits of protein kinases (Bourne and $\mathrm{Ni}$ coll, 1993); and (c) structural proteins and cell adhesion proteins, presumably involved in the formation or reorganization of synaptic contacts (Rosenthal et al., 1987; Bailey et al., 1992). None of these molecules is "new" or coding for the acquired information; rather, they are all permanent constituents of the CNS, and some of them (for example, enolase, ependymin, $\mathrm{S}-100$, or tubulin) occur even in relatively high concentration. Nevertheless, there appears to be a demand for de novo protein synthesis during memory consolidation, as intervention with either transcription or translation induces amnesia most effectively around the time of training (Agranoff et al., 1967; Neale et al., 1973; Thut and Lindell, 1974; Squire and Barondes, 1976; reviewed by Rainbow, 1979).

This is particularly obvious in the case of ependymin, which occurs in high amounts in goldfish brain cytoplasm $(2.4 \%$ of the total protein contents) and brain extracellular fluid [15.4\% of the soluble extracellular protein (Schmidt and Lapp, 1987)]. In spite of these high concentrations, ependymin is de novo synthesized and secreted after acquisition of various training tasks (Shashoua, 1979; Schmidt, 1987, 1989; Shashoua and Hesse, 1989). Secretion is preceded by a temporary decrease in the steady-state concentration of soluble ependymin in the extracellular brain fluid [measured independently in radioimmunoassays by Schmidt (1987) and in ELISA by Shashoua and Hesse (1989)], indicating that some of this protein is "used up" during the memory consolidation process, e.g., by uptake into neurons that had been activated during acquisition or by binding to components of the extracellular matrix, in particular to laminin (Schmidt et al., 1991), possibly to collagen (Schwarz et al., 1993), and to other ependymin molecules [polymerization (compare Shashoua et al., 1990; Schmidt, 1995)]. The decrease in extracellular ependymin content may actually provide a signal for ependymin mRNA induction
(Rother et al., 1995). Consumption of ependymin molecules after learning is also suggested by the notion that the relative increase in the message (Rother et al., 1995) was higher than that of the translation product (Schmidt, 1989).

Apparently, at any particular moment, only the small fraction of newly synthesized (monomer?) ependymin molecules is available or "activated" for participation in the biochemical reactions of memory consolidation. Once used, they are not disposable any more and have to be replaced by new molecules. Such a mode of action would also explain why inactivation of secreted ependymins before training did not interfere with memory consolidation (Piront and Schmidt, 1988). Results from the present study support the following proposed mechanism: Antisense S-ODNs prevent translation without interference with the preexisting, translated protein. Obviously, it is sufficient to block de novo synthesis of ependymin molecules to induce amnesia.

It is not yet known whether S-ODNs interfere with translation by steric hindrance of the ribosome, or whether they degrade the RNA strand of the DNARNA duplex by RNaseH activation (compare Brysch and Schlingensiepen, 1994). Whatever the actual mechanism may be, our data clearly indicate that 18 mer S-ODNs injected into the perimeningeal fluid reach the leptomeninx and are incorporated into fibroblasts. Although most of the injected S-ODN was recovered in these ependymin-synthesizing cells, we assume that preferential labeling was not due to specific hybridization with the complementary ependymin mRNA, but rather caused by the high endocytotic activity of endomeningeal fibroblasts.

In conclusion, antisense intervention experiments demonstrate that only newly synthesized ependymin molecules are involved in memory consolidation, probably because they have not yet undergone irreversible changes that lead to binding to the extracellular matrix or incorporation into cellular elements. Our experiments are possibly the first to demonstrate a specific effect of antisense S-ODNs on memory formation. While this work was in progress, other experiments revealed a biphasic increase in levels of the "immediate early gene" transcripts junB und c-fos after brightness discrimination training on rats and an inhibitory influence of anti-c-jun S-ODNs (but not anti-junB) on the performance of the task in training and test sessions (Tischmeyer et al., 1994). It is anticipated that the easy applicability of antisense S-ODNs in vivo will make them valuable tools for scientific research and suitable agents for medical care, with a specificity as good as that of antibodies.

Acknowledgment: We are most grateful to Susanne Gathmann for excellent technical assistance, to G. Strieder and M. Brümmer (Universität Frankfurt) for designing and building the computerized shuttle-box, and to the Deutsche 
Forschungsgemeinschaft for financial support (grants Schm 478/4-4 and Gr 650/5-2).

\section{REFERENCES}

Agranoff B. W., Davis R. E., Casola L., and Lim R. (1967) Actinomycin $\mathrm{D}$ blocks formation of memory of shock-avoidance in goldfish. Science 158, 1600-1601.

Bailey C. H., Chen M., Keller F., and Kandel E. R. ( 1992) Serotoninmediated endocytosis of apCAM: an early step of learningrelated synaptic growth in Aplysia. Science 256, 645-649.

Bock E. and Dissing J. (1975) Demonstration of enolase activity connected to the brain specific protein 14-3-2. Scand. J. Immunol. 4 (Suppl. 2), 31-36.

Bourne H. R. and Nicoll R. (1993) Molecular machines integrate coincident synaptic signals. Cell 72/Neuron 10 (Suppl.), 6575 .

Brysch W. and Schlingensiepen K.-H. (1994) Design and application of antisense oligonucleotides in cell-culture, in-vivo and as therapeutic agents. Cell. Mol. Neurobiol. 14, 557-568.

Brysch W., Rifai A., Tischmeyer W., and Schlingensiepen K.-H. (1995) Rational drug design, pharmacokinetics and organ uptake of antisense phosphorothioate oligodeoxynucleotides invivo, in Antisense Oligonucleotide Therapy: Current Status (Agrawal S., ed), in press. Humana Press, Totowa, New Jersey.

Davis H. P. and Squire L. R. (1984) Protein synthesis and memory: a review. Psychol. Bull. 96, 518-559.

Eckstein F. (1983) Phosphorothioate analogues of nucleotidestools for the investigation of biochemical processes. Angew. Chem. 22, 423-506.

Hydén H. and Egyhazi E. (1964) Changes in RNA content and base composition in cortical neurons of rats in a learning experiment involving transfer of handedness. Proc. Natl. Acad. Sci. USA 52, 1030-1035.

Königstorfer A., Sterrer S., Eckerskorn C., Lottspeich F., Schmidt R., and Hoffmann W. (1989) Molecular characterization of an ependymin precursor from goldfish brain. $J$. Neurochem. 52, $310-312$.

Neale J. H., Klinger P. D., and Agranoff B. W. (1973) Camptothecin blocks memory of conditioned avoidance in the goldfish. Science 179, 1243-1246.

Piront M.-L. and Schmidt R. (1988) Inhibition of long-term memory formation by anti-ependymin antisera after active shock-avoidance learning in goldfish. Brain Res. 442, 53-62.

Rainbow T. C. (1979) Role of RNA and protein synthesis in memory formation. Neurochem. Res. 4, 297-312.

Rosenthal A., Chan S. Y., Henzel W., Haskell C., Kuang W.-J., Chen E., Wilcox J. N., Ullrich A., Goeddel D. V., and Routtenberg A. (1987) Primary structure and mRNA localization of protein $\mathrm{F}$, a growth-related protein kinase $\mathrm{C}$ substrate associated with synaptic plasticity. EMBO J. 6, 3641-3646.

Rother S., Schmidt R., Brysch W., and Schlingensiepen K.-H. (1995) Learning-induced expression of meningeal ependymin mRNA and demonstration of ependymin in neurons and glial cells. J. Neurochem. 65, 1456-1464.

Schlingensiepen K.-H. and Brysch W. (1992) Phosphorothioate oligomers: inhibitors of oncogene expression in tumor cells and tools for gene function analysis, in Gene Regulation-Biology of Antisense RNA and DNA (Erickson R. and Izant J., eds), pp. 317-328. Raven Press, New York.

Schmidt J. T., Schmidt R., Lin W., Jian X., and Stürmer C. A. O. (1991) Ependymin as a substrate for outgrowth of axons from cultured explants of goldfish retina. J. Neurobiol. 22, 40-54.

Schmidt R. (1987) Changes in subcellular distribution of ependym- ins in goldfish brain induced by learning. J. Neurochem. 48, $1870-1878$.

Schmidt R. (1989) Glycoproteins involved in long-lasting plasticity in the teleost brain, in Progress in Zoology, Vol. 37: Fundamentals of Memory Formation: Neuronal Plasticity and Brain Function (Rahmann H. and Lindauer M., eds), pp. 327-339. Fischer-Verlag, Stuttgart.

Schmidt R. (1995) Cell-adhesion molecules in memory formation. Behav. Brain Res. 66, 65-72.

Schmidt R. and Lapp H. (1987) Regional distribution of ependymins in goldfish brain measured by radioimmunoassay. Neurochem. Int. 10, 383-390.

Schmidt R. and Shashoua V. E. (1981) A radioimmunoassay for ependymins $\beta$ and $\gamma$ : two goldfish brain proteins involved in behavioral plasticity. J. Neurochem. 36, 1368-1377.

Schmidt R. and Shashoua V. E. (1983) Structural and metabolic relationships between goldfish brain glycoproteins participating in functional plasticity of the central nervous system. J. Neurochem. 40, 652-660.

Schmidt R., Rother S., and Schwerdtfeger W. K. (1990) Glycoproteins of the extracellular matrix mediate plasticity in the CNS, in The Forebrain in Nonmammals: New Aspects of Structure and Development (Schwerdtfeger W. K. and Germroth P., eds), pp. 17-28. Springer-Verlag, Berlin.

Schmidt R., Brysch W., Rother S., and Schlingensiepen K.-H. (1993) Molecular analysis of cell adhesion mechanisms in memory formation, in Gene-Brain-Behaviour (Elsner N. and Heisenberg M., eds), p. 5. Thieme, Stuttgart.

Schwarz H., Müller-Schmid A., and Hoffmann W. (1993) Ultrastructural localization of ependymins in the endomeninx of the brain of the rainbow trout: possible association with collagen fibrils of the extracellular matrix. Cell Tissue Res. 273, 417425.

Shashoua V. E. (1979) Brain metabolism and the acquisition of new behaviors. III. Evidence for secretion of two proteins into the brain extracellular fluid after training. Brain Res. 166, 349358.

Shashoua V. E. and Hesse G. (1989) Classical conditioning leads to changes in extracellular concentrations of ependymin in goldfish brain. Brain Res. 484, 333-339.

Shashoua V. E. and Moore M. E. (1978) Effect of antisera to $\beta$ and $\gamma$ goldfish brain proteins on the retention of a newly acquired behavior. Brain Res. 148, 441-449.

Shashoua V. E. and Schmidt R. (1987) Learning and memory: neurochemical aspects, in Encyclopedia of Neuroscience (Adelman G., ed), pp. 577-579. Birkhäuser, Boston.

Shashoua V. E., Hesse G. W., and Milinazzo B. (1990) Evidence for the in vivo polymerization of ependymin: a brain extracellular glycoprotein. Brain Res. 522, 181-190.

Squire L. R. and Barondes S. H. (1976) Amnesic effect of cycloheximide not due to depletion of a constitutive brain protein with short half-life. Brain Res. 103, 183-190.

Thut P. D. and Lindell T. J. (1974) $\alpha$-Amanitin inhibition of mouse brain form II ribonucleic acid polymerase and passive avoidance retention. Mol. Pharmacol. 10, 146-154.

Tischmeyer W., Grimm R., Schicknick H., Brysch W., and Schlingensiepen K.-H. (1994) Sequence-specific impairment of learning by c-jun antisense oligonucleotides. Neuroreport $\mathbf{5}$, $1501-1504$.

Warren W. J. and Vella G. (1993) Analysis of synthetic oligodeoxyribonucleotides by capillary gel electrophoresis and anion-exchange HPLC. Biotechniques 14, 598-606.

Wu-Pong S., Weiss T. L., and Hunt C. A. (1994) Antisense c-myc oligonucleotide cellular uptake and activity. Antisense Res. Dev. 4, 155-163. 